\title{
Problems in bariatric patient care - challenges for dieticians
}

\author{
Małgorzata Kostecka, Monika Bojanowska \\ Department of Chemistry, University of Life Science, Lublin, Poland
}

Videosurgery Miniinv 2017; 12 (3): 207-215

DOI: https://doi.org/10.5114/wiitm.2017.70193

\begin{abstract}
Obesity management options include a low-calorie diet, behavioral therapy, regular physical activity and pharmacological therapy. However, treatment failure is frequently encountered, most of these methods are ineffective, and a positive outcome is rarely maintained in the long term. In morbidly obese patients, bariatric surgery is considered the most effective treatment for obesity as well as the accompanying diseases. Bariatric surgery promotes much greater weight loss than conservative treatment, regardless of the applied surgical technique. Bariatric surgery patients should receive professional perioperative (preoperative, intraoperative and postoperative) care from a multidisciplinary team of specialists, including a bariatric surgeon, a general practitioner, a dietitian and a health psychologist. Patients require postoperative nutritional counseling to be able to stabilize their weight and maintain long-term weight loss after surgery. Patients are guided by bariatric dietitians through the process of adopting new eating habits and behavior, learning how to make healthy food choices.
\end{abstract}

Key words: obesity, bariatric surgery, weight loss.

\section{Introduction}

In recent years, bariatric surgery has become the most effective weight loss therapy for moderately and morbidly obese people $[1,2]$. Conservative treatment can induce the loss of $5-10 \%$ of body weight, whereas bariatric surgery leads to weight loss of 50-60 kg, which delivers significant health benefits [3]. Bariatric surgery has a noticeable effect on the patients' health, but significant weight loss and reduced food intake can lead to nutritional and vitamin deficiencies [4]. For this reason, physicians and dieticians play a very important role during perioperative care and 6-12 months after surgery. Patients have to be told about what is expected of them both before and after the operation. They should be prepared for the procedure and informed about the importance of physical and mental wellbeing for further treatment. During bariatric therapy, patients should remain in the care of a team of specialists. The failure to ob- serve bariatric recommendations, uncontrolled dietary supplementation or restrictive eating can lead to serious health problems, metabolic dysfunctions, and impaired absorption of nutrients and vitamins, which prolongs the preparatory period for weight-loss surgery [5]. After the operation, patients should work with dieticians and physicians to develop new eating habits and control their body weight. Regular consultations with a dietician should be scheduled 1, 3, 6, 9 and 12 months after the surgery, and then once every year. Unfortunately, consultations with a dietician are not reimbursed by the Polish health insurance system, and many patients have to pay for their visits. Patients who do not consult a dietician are at much greater risk of regaining the lost weight [6].

\section{Preoperative assessment}

The main aim of preoperative assessment is to determine whether the patient fulfills the criteria

\footnotetext{
Address for correspondence

Małgorzata Kostecka PhD, Department of Chemistry, University of Life Science, 15 Akademicka St, 20-950 Lublin, Poland, phone: +48 507052 713, e-mail: julka-portal@wp.pl
} 
for bariatric surgery. Patients are evaluated for concomitant health conditions based on the body mass index (BMI) score, chronic diseases associated with excessive body weight, and risk factors that can contribute to disease and premature death.

The potential candidates for bariatric surgery are persons with BMI higher than $40 \mathrm{~kg} / \mathrm{m}^{2}$ or BMI of 35$40 \mathrm{~kg} / \mathrm{m}^{2}$ who have been diagnosed with concomitant illnesses, in particular type 2 diabetes, lipid metabolism disorders and ischemic heart disease [7]. In 2011, laparoscopic adjustable gastric bands (LAGB) were approved for use by the Food and Drug Administration (FDA) in patients with BMI of $30-35 \mathrm{~kg} /$ $\mathrm{m}^{2}$, but the inclusion criteria differ across countries. In most cases, patients with the above BMI are qualified for LAGB if they suffer from diabetes [8]. According to recent research, surgical treatment of diabetic patients should be a priority because it reduces the overall treatment costs $[9,10]$. Bariatric surgery can also deliver health benefits for patients suffering from degenerative joint disease, sleep apnea, gastroesophageal reflux, non-alcoholic fatty liver diseases, hypoventilation syndrome and asthma [11, 12].

A detailed dietary assessment is an important step in the process of determining a patient's eligibility for bariatric surgery. During the assessment, a dietician obtains information about the patient's eating habits and previous attempts to lose weight. The patient is also screened for diseases that could increase perioperative risk as well as behaviors that could complicate postoperative recovery, in particular:

- lack of appropriate medical care,

- inability to remain in postoperative care for a long period of time,

- limited mobility and functional abilities, lack of long-term support from family or friends,

- alcohol or drug dependence,

- sudden, life-threatening illnesses,

- autoimmune diseases.

The exclusion criteria for bariatric surgery include personality disorders, severe depression and psychiatric disorders, but in some circumstances, patients may be admitted for surgery upon the recommendation of a psychiatrist who has experience in treating obese patients. Other concomitant diseases that may complicate surgery include celiac disease and inflammatory bowel disease, because postoperative complications such as deep vein thrombosis (DVT) [13] and pulmonary embolism (PE) significantly increase the risk of death in those patients. Celiac dis- ease also impairs nutrient absorption, which can lead to malnutrition, iron deficiency anemia, vitamin B and folic acid deficiency, and vitamin K-dependent clotting factor deficiency $[14,15]$.

Bariatric patients have to be aware that weight loss is a long process that could require pharmacological therapy. Some patients, in particular those undergoing Roux-en-Y gastric bypass surgery (RYGB), have to avoid non-steroidal anti-inflammatory drugs, which increase the risk of gastric and jejunal ulcers $[16,17]$.

Preoperative assessment should support the identification of habits and behaviors that could increase the risk of perioperative and postoperative complications. Smoking delays convalescence, contributes to stomatal ulceration and increases the risk of death [18]. The psychological profiles of bariatric surgery candidates range from depression, anxiety and fear of being alone to social anxiety and fear of social rejection [19]. Many bariatric patients lose up to $60 \%$ of excess weight in 1 year, which could be a traumatic experience. Patients who are emotional eaters should receive special care [5]. In Boniecka's research stress was found to be one of the most frequent causes of eating between meals, and moreover a large part of the patients reported an increase in appetite due to stressful situations [20]. Regular medical checkups before and after surgery as well as family support are essential because dramatic weight loss is a life-changing experience.

\section{Dietary management}

Patients considering bariatric surgery should be able to consult a dietician before the operation. During the consultation, patients are provided with information about the dietary regimen throughout the weight loss process. Consultations take place individually or in groups, and patients learn about postoperative options as well as the challenges they will face and the sacrifices they will have to make after the procedure. Patients have to be aware that the preoperative diet could save their lives, and they should be ready to embark on the prescribed dietary regimen as soon as possible. Weight loss surgery changes the way patients experience hunger and satiety, but it does not change their environment. Patients need to realize that they will face the same temptations after surgery; therefore, they need new methods and tools for overcoming self-defeating be- 
haviors. Patients will have to learn how to shop for food immediately after the operation and in the future. Dietary consultations should begin a minimum of 6 weeks before the operation; they should be based on a detailed assessment and the results of blood tests and glucose tolerance tests. A dietician will evaluate the patient's attitude towards future changes and his or her motivation, and will set realistic goals for the future [21]. The patient should also be provided with a set of weight-management benchmarks for controlling his/her diet and lifestyle. Patients are advised to eat regular meals (at least 4 during the day), plan food purchases in advance and prepare low-calorie meals. A $1000 \mathrm{kcal}$ diet is recommended over a period of 4 weeks to enable the patient to adjust to the postoperative reduction in the quantity and quality of consumed food. Patients should eat breakfast within $1 \mathrm{~h}$ of waking and subsequent meals every 3-4 h. They should learn new cooking techniques to reduce the content of fat and aromatic hydrocarbons in meals [22]. To prepare for the postoperative diet, patients should always eat meals at the table, fully focus on the meal, cut their food into small chunks, chew food for longer and refrain from drinking liquids during the meal [23]. They may be prescribed orlistat ( 3 tablets daily before main meals) to speed up preoperative weight loss [24, 25].

Morbidly obese patients have very low levels of physical activity. Many of them find it difficult to exercise due to joint pain, respiratory problems and very low fitness levels. According to observations, physical activity speeds up convalescence, which is why patients should be encouraged to undertake some form of physical activity before bariatric surgery [26].

In some bariatric clinics, patients have to meet specific requirements to qualify for surgery. Patients may be required to reduce their body weight by $5-10 \%$. Preoperative weight loss decreases the risk of surgical complications, but its positive effect on long-term postoperative outcome has not been scientifically confirmed [13, 27].

Obesity may lead to nutritional deficiencies; therefore, surgery candidates should undergo nutrient panel blood tests. They should be particularly screened for iron (total iron binding capacity (TIBC), ferritin and transferrin levels), folic acid (in particular in women of reproductive age; however, female patients should wait 18-24 months after surgery before getting pregnant), vitamin $B_{12}$, thiamine (vitamin $B_{1}$ ), vitamin $D$ and calcium levels. Anemia was found amongst $10-22 \%$ pre-operatively [28]. This is most likely due to the fact that the diets of obese patients are calorie-dense, high in carbohydrates and fats, and low in vitamins and minerals.

Nutritional deficiencies should be addressed before surgery because the relevant risk increases significantly after the operation. A retrospective study of patients qualified for RYGB surgery revealed iron deficiency in $44 \%$ of the subjects, thiamine deficiency in $29 \%$, and vitamin D deficiency in $68 \%$ [29]. The diets of patients suffering from nutritional deficiencies should be supplemented. According to practical experience, an oral vitamin $B_{12}$ supplement administered in a daily dose of $350 \mu \mathrm{g}$ offers effective treatment for most patients [30, 31].

Assessment of the risk of malnutrition should be done before bariatric surgery. Calcium, albumin, iron, zinc, magnesium, phosphorus, folic acid and vitamin $B_{12}$ and $D$ levels must be assessed as part of the preoperative routine evaluation [32].

\section{Surgical techniques and diet modification}

Laparoscopic gastric banding (LGB) is the least invasive surgical technique and does not require gastric incisions or removal and rerouting of the intestines [33]. This type of surgery generally leads to the loss of $55-60 \%$ of excessive weight. It does not impair nutrient absorption, which eliminates the need for vitamin and mineral supplementation after the operation. After LGB surgery, patients have to learn to eat slowly and chew their food for longer to avoid vomiting after meals [34].

Roux-en-Y gastric bypass is a standard technique in bariatric surgery. The smaller stomach is connected directly to the jejunum, and ingested food bypasses the duodenum, which significantly reduces the surface area for absorption. This technique is highly effective for weight loss, but malabsorption can lead to nutritional and vitamin deficiencies. For this reason, RYGB patients should be regularly monitored and prescribed dietary supplements [35].

Sleeve gastrectomy (SG) is a new and increasingly popular surgical technique in bariatric treatment [36]. The volume of the stomach is reduced by around $70-80 \%$ to $100-150 \mathrm{ml}$, which forces the patient to significantly limit his/her food intake. The procedure does not affect the intestines, so dietary 
supplementation is not required, with the exception of B-group vitamins (in particular $B_{1}$ and $B_{12}$ ) [37]. Laparoscopic sleeve gastrectomy increased significantly from 2009 to 2014 (+42.9\%), and at present it represents the most popular bariatric procedure performed in Poland [38].

\section{Postoperative dietary guidelines}

Patients should be aware that bariatric surgery alone without a suitable diet or physical activity will not lead to sustained weight loss [39]. Dietary guidelines are similar for all types of bariatric surgery, and modifications are introduced subject to individual need. After the operation, patients should eat a low-calorie and protein-rich diet, choose foods with the right volume and consistency, and drink the appropriate amount of fluids [40]. The right diet will enable patients to avoid unpleasant sensations after surgery, such as stomach cramps, vomiting, diarrhea, constipation, dumping syndrome and gastroesophageal reflux.

After bariatric surgery, the new diet should be introduced in 5 stages:

- liquid diet,

- fortified liquid diet,

- easily digestible soft diet,

- easily digestible solid diet,

- low-calorie diet.

In the first 6-8 weeks after surgery, a more restrictive diet should be followed to promote healing of surgical wounds and enable the gastric tract to accommodate to the changes. Energy and nutrient intake should be balanced to prevent the loss of lean body mass and speed up wound healing [40]. A liquid neutral and sugar-free diet should be followed in the first 3 days after surgery, and nutritional liquids should be introduced in the following days [41]. A part of the liquid diet can be administered intravenously, and orally administered fluids should be limited to tolerable amounts, beginning with 15-30 ml, and gradually increasing the daily intake to $1500 \mathrm{ml}$. Liquids should administered in small amounts, and patients should avoid drinking through a straw, which causes excess air in the stomach. Liquids should be lukewarm, preferably at body temperature, to avoid irritation of the gastrointestinal mucosa [42]. Three to seven days after surgery, daily liquid intake can be increased to $1900 \mathrm{ml}$. Liquids should be consumed $30 \mathrm{~min}$ before or 30-60 min after a meal $[40,42]$ to prevent the dumping syndrome. The dumping syndrome is observed mainly in RYGB patients, and less frequently in SG patients. High-risk patients should be identified before the surgery [43].

The refeeding syndrome increases insulin secretion, decreases glucagon production, disturbs protein synthesis and decreases phosphorus, potassium and magnesium levels in the blood serum. Electrolyte imbalance can be a life-threatening condition during postoperative care [44], and early diagnosis minimizes the risk of death [45].

The postoperative diet is planned individually, subject to the patient's nutritional requirements and tolerance levels. Nutritional liquids should be introduced in the first week after surgery, including skimmed milk, soy milk, skimmed natural yogurt and blended soups based on lean poultry and vegetable stock (carrot, parsley, celery). Liquids can be fortified with soy protein isolate or whey protein powder at up to $20 \mathrm{~g}$ per serving [40]. This option is particularly recommended for patients suffering from lactose intolerance who are at higher risk of protein deficiency. The liquid diet should be maintained for 2 weeks after the operation. In successive weeks, liquids should be gradually replaced with soft foods consisting of ground low-fat and high-protein products such as eggs, fish, poultry, lean meat, lowfat cottage cheese or boiled beans [40, 46].

Vegetables can be gradually introduced if the diet is well tolerated by the patient. Food should be chewed for longer, and it should be divided into small portions (around 1/4 cup) served 5-6 times a day. The dietician should monitor the patient's daily protein intake. The diet should be rich in wholesome protein in a minimum daily amount of $60 \mathrm{~g}$ [40]. Gastric bypass surgery increases protein demand by $30 \%$, and daily protein intake should reach around $120 \mathrm{~g}$ [23]. Four to 6 weeks after the operation, boiled soft vegetables and soft, peeled fruit may be introduced. Fruit should be served as juice diluted with water or in purée form. The number of meals per day remains the same, but portion size is increased to $1 / 2$ cup. Protein intake is increased to 60-80 g/day. In the first months after surgery, patients are advised to avoid foods that are not easily digestible, including red meat, chicken, turkey, products made with white flour, foods with high sugar and high fat content, raw fruits and vegetables with high fiber content [40]. 
Patients should receive detailed dietary guidelines from the dietician to ensure that the weightloss process is successful. In successive months after the operation, portions should still be small, and daily protein intake should not be less than $60 \mathrm{~g}$. Liquids should be consumed $30 \mathrm{~min}$ before or 30-60 min after a meal. Meals should be eaten regularly, in a quiet atmosphere, and food should be chewed for longer. Two months after the procedure, portion size can be increased to $150 \mathrm{ml}$ per meal, daily protein intake should be $60-80 \mathrm{~g}$, and daily liquid intake should be 1500-1900 ml [23, 47]. The intake of high-energy products should be reduced to 700-900 kcal per day in the first few months after surgery. In successive months, daily energy intake should be adjusted to the patient's age, height and weight, and it usually ranges from 1000 to $1200 \mathrm{kcal}$ [46]. Patients should drink at least $1500 \mathrm{ml}$ of fluids per day. The recommended beverages include water, weak tea, chamomile and mint tea. Alcohol, carbonated drinks, sweetened beverages, fruit and vegetable juice can promote indigestion and should be avoided in the first year after surgery [40].

In the USA and other countries where bariatric surgery is the leading type of obesity treatment, a food pyramid has been designed for patients $[48,49]$. Dietary recommendations are presented in graphic form, and the pyramid helps patients to make the right food choices and adjust their portion size. The pyramid includes physical activity which contributes to weight loss.

\section{Postoperative supplementation}

Bariatric patients should be prescribed vitamin and mineral supplements to avoid the risk of nutritional deficiencies. The recommended dose is 1 tablet taken twice a day. Liquid or chewable supplements are preferred [50].

The following supplementation regimen is recommended as of the third day after surgery:

- calcium (calcium citrate) at 1200-1500 mg/day,

- vitamin $D_{3}$ at 1000-2000 lU/day,

- vitamin $B_{12}$ at $500 \mathrm{mg} /$ day for oral supplements or $1000 \mathrm{mg} / \mathrm{month}$ for intramuscular injections.

Dietary supplements containing folic acid (400 mg/ day) and elemental iron (65-80 mg/day), preferably with vitamin $C$, are also recommended. Routine administration of folic acid, vitamin $B_{12}$ and iron is not required in patients who have undergone lapband surgery [51].

According to observations, bariatric patients increase their intake of vitamin, mineral and iron supplements in line with dietary recommendations [52]. However, a study of RYGB surgery patients, conducted 12 months after the procedure, revealed very low levels of hemoglobin, ferritin, zinc and vitamin $B_{12}$, and increased plasma C-reactive protein levels [53]. Thirty-six months after the procedure, around 15\% of patients using multiple supplements were diagnosed with ferritin and vitamin $B_{12}$ deficiency as well as anemia [54]. Folic acid deficiency and high homocysteine levels were also reported [55].

\section{The influence of bariatric surgery on bone metabolism}

Obesity is an independent risk factor for vitamin D deficiency. Calcium deficiency and elevated parathormone (PTH) levels are also frequently reported in bariatric surgery candidates. A study of 279 morbidly obese subjects who were candidates for gastric bypass surgery was conducted to address the above concerns. Blood samples were analyzed to determine the serum concentrations of $25(\mathrm{OH}) \mathrm{D}$, calcium, alkaline phosphatase (AP), intact PTH and 1,25-dihydroxyvitamin D. Calcium and AP serum levels were within the norm in $88 \%$ of the subjects. Vitamin D deficiency (serum 25-hydroxyvitamin D levels $\leq 20 \mathrm{ng} / \mathrm{ml}$ ) was reported in $60 \%$ of the patients, and elevated PTH levels were found in $48 \%$ of the subjects [56]. According to most studies, vitamin D supplements administered at 1000-5000 IU/day effectively increase 25(OH)D levels above $30 \mathrm{ng} / \mathrm{ml}$ [57], but they may not be sufficient in patients with elevated serum PTH levels [58].

Research has also demonstrated that vitamin $D_{3}$ supplements induce a smaller increase in serum $25(\mathrm{OH}) \mathrm{D}$ levels in obese subjects than in persons with a healthy body weight, which suggests that the hydroxylation of vitamin D to $25(\mathrm{OH}) \mathrm{D}$ is compromised in the liver of obese patients [59]. Mineral deficiencies increased with time after bariatric surgery. Calcium deficiency was noted in $10-25 \%$ of the patients 2 years after the procedure and in 25-48\% of the subjects 4 years after the surgery. Deficiency of $25(\mathrm{OH}) \mathrm{D}_{3}$ was reported in $17-52 \%$ of the patients in the first 2 years and in $50-63 \%$ of the subjects 4 years after the procedure [55]. The progressing 
deterioration in bone metabolism after bariatric surgery is caused by several factors [60], including decreased nutrient absorption. Pharmacological treatment administered for preventive purposes and to treat associated conditions, such as ulceration at the site of gastrojejunal anastomosis, can also compromise nutrient absorption and bone health. Rapid weight loss in itself is a risk factor that can impair bone metabolism. The patients' diet should be carefully planned to prevent nutritional deficiencies, and bisphosphonate treatment may be required in some cases. According to a meta-analysis of recent studies, bariatric surgery may contribute to a deficiency of calcium and fat-soluble vitamins, mainly vitamin $\mathrm{D}$, which is a risk factor for osteopenia and osteoporosis [61].

\section{Postoperative challenges}

The most rapid weight loss is observed in the first 6 months after surgery, and it can last up to 18 months. Dietary guidelines for bariatric patients have to be formulated with great caution to ensure that they are not demotivating and do not lead to malnutrition [18].

During dietary consultations, patients should be encouraged to analyze the influence of cultural factors, financial concerns, lifestyle choices and personal preferences on their diets. Meals should be nutritionally balanced and should be composed of lean meat, fruit, vegetables and whole grain products. Patients who opt for a vegetarian diet should learn how to replace meat with plant-based foods.

Patients have to be adequately motivated to ensure that they are not discouraged when they suddenly stop losing weight. According to postoperative statistics, less than $5 \%$ of patients lose $100 \%$ of excessive weight, and their body mass increases by around $20-25 \%$ ten years after surgery. Patients should be provided with detailed information about all stages of the weight loss process, which will enable them to prepare mentally for the necessary changes in their dietary habits. It should be noted that nutritional deficiencies can follow not only from the failure to follow the prescribed diet, but also from a highly restrictive approach to dieting $[62,63]$.

Gastric resection and gastric bypass surgery reduce hunger and increase satiety. Patients have to learn to listen to their own bodies and restrict the amount of food that can be accommodated by the new stomach size. Eating regular meals in the right proportions and in a quiet atmosphere is crucial for sustained weight maintenance. Patients should remain in long-term postoperative care to develop new eating habits, adopt a healthy life style and become physically active. According to recent research, the patients' quality of life improves after bariatric surgery. These changes are experienced immediately after the procedure, and they are most visible in the first year after the operation. The patients' quality of life does not deteriorate in successive years, but it continues to be somewhat lower in comparison with non-obese subjects [64].

Rapid and sustained weight loss contributes to an improvement in mental wellbeing. Patients find it easier to cope with the demands of daily life, they no longer require assistance, and they can begin to exercise and become more physically active, which visibly improves their quality of life. Bariatric surgery can reverse some diseases linked with obesity, including diabetes, sleep apnea and hypertension, which improves the patients' daily wellbeing and prolongs their life expectancy [65].

Unfortunately, some bariatric patients do not experience an improvement in their quality of life despite ongoing treatment and weight loss. The above could result from postoperative complications such as gastroesophageal reflux [66], depression or lack of professional medical care, including dietary advice [67]. Patients' mental health should be regularly monitored, because morbid obesity often results from the subjects' inability to cope with daily life. Bariatric surgery can change the patients' external appearance, but additional work is required to promote positive psychological change. For this reason, counseling support is essential throughout the entire weight loss process. Patients who fail to cope with mental issues and are not provided with dietary guidance are at much higher risk of lapsing back into their old eating habits. According to research, the above affects around $5 \%$ of bariatric patients [68].

\section{Conclusions}

Bariatric surgery is the most effective weight loss treatment in morbidly obese patients, but it may lead to complications and undesirable side effects. Non-invasive surgical methods are safer and more effective than traditional open surgery. Modern 
bariatric surgery relies mainly on laparoscopic techniques, which are characterized by reduced postoperative pain, shorter hospitalization, faster recovery and an improved esthetic outcome. Early outcomes of laparoscopic vertical banded gastroplasty point to a significant decrease in the incidence of perioperative complications in comparison with open surgery that leads to similar weight loss. Dieticians play a very important role in preparing patients for the operation and providing them with support after the surgery. A balanced diet is the key to successful weight loss in all stages of treatment. Bariatric patients should receive comprehensive care at a minimum from 6 months before to 24-36 months after surgery. The medical team should comprise an endocrinologist, a surgeon, a dietician and a psychologist. Patients who receive comprehensive medical treatment and personalized dietary guidelines lose weight faster and experience greater improvement in their quality of life.

\section{Conflict of interest}

The authors declare no conflict of interest.

\section{References}

1. Kissler HJ, Settmacher U. Bariatric surgery to treat obesity. Semin Nephrol 2013; 33: 75-89.

2. Piché ME, Auclair A, Harvey J, et al. How to choose and use bariatric surgery in 2015. Can J Cardiol 2015; 31: 153-66.

3. Stanowski E, Wyleżoł M. Rozwój chirurgicznego leczenia otyłości na świecie i w Polsce. Post Nauk Med 2009; 7: 498-501.

4. de'Angelis N, Carra MC, Vincenzi F. Gluten-free diet in obese patients with celiac disease: an enemy of the bariatric surgeon? Obes Surg 2012; 22: 995-6.

5. Kushner R, Still C. Nutrition and Bariatric Surgery, CRC Press Book 2015.

6. Hwang KO, Childs JH, Goodrick GK, et al. Explanations for unsuccessful weight loss among bariatric surgery candidates. Obes Surg 2009; 19: 1377-83.

7. Endevelt R, Ben-Assuli O, Klain E, et al. The role follow-up in the success of bariatric surgery. Surg Obes Relat Dis 2013; 9: 963-8.

8. Dąbrowiecki S. Zasady kwalifikacji chorych z otyłością olbrzymią do leczenia operacyjnego. Post Nauk Med 2009; 22: 502-5.

9. The American Society for Metabolic and Bariatric Surgery (ASMBS), Bariatric surgical procedures: http://asmbs.org/patients/bariatric-surgery-procedures.

10. Lopes EC, Heineck I, Athaydes G, et al. Is bariatric surgery effective in reducing comorbidities and drug costs? A systematic review and meta-analysis. Obes Surg 2015; 25: 1741-9.

11. YU J, Zhou X, Li L, et al. The long-term effects of bariatric surgery for type 2 diabetes: systematic review and meta-analysis of randomized and non-randomized evidence. Obes Surg 2014; 25: $143-58$
12. Paluszkiewicz R, Kalinowski P. The role of bariatric surgery in the treatment of obstructive sleep apnea. Pneumonol Alergol Pol 2007; 75: 44-9.

13. Raport of the WHO consultation. Obesity: preventing and managing the global epidemic. World Health Organization. Tech Rep Ser 2000; 894: 1-253.

14. Krotki MA. Rola dietetyka w opiece nad chorymi poddawanymi operacjom bariatrycznym. Post Nauk Med 2015; 28: 667-72.

15. Valletta E, Fornaro M, Cipolli M, et al. Celiac disease and obesity: need for nutritional follow-up after diagnosis. Eur J Clin Nutr 2010; 64: 1371-2.

16. Hakkarainen TW, Steele SR, Bastaworous A, et al. Nonsteroidal anti-inflammatory drugs and the risk for anastomotic failure: a report from Washington State's Surgical Care and Outcomes Assessment Program (SCOAP). JAMA Surg 2015; 150: 223-8.

17. Sasse KC, Ganser J, Kozar M, et al. Seven cases of gastric perforation in Roux-en-Y gastric bypass patients: what lessons can we learn? Obes Surg 2008; 18: 530-4.

18. Gesquiere I, Augustijns P, Lannoo M, et al. Barriers in the approach of obese patients undergoing bariatric surgery in Flemish hospitals. Obes Surg 2015; 25: 2153-9.

19. Mason ME, Jalagani H, Vinik Al. Metabolic complications of bariatric surgery: diagnosis and management issues. Gastroenterol Clin North Am 2005; 34: 25-33.

20. Boniecka I, Wileńska H, Jeznach-Steinhagen A. Stress as a factor contributing to obesity in patients qualified for bariatric surgery - studies in a selected group of patients (a pilot study). Videosurgery Miniinv 2017; 12: 60-7.

21. Magallares A, Schomerus G. Mental and physical health-related quality of life in obese patients before and after bariatric surgery: a meta-analysis. Psych Health Med 2014; 20: 165-78.

22. Wyatt HR, Grunwald GK, Mosca CL, et al. Long-term weight loss and breakfast in subjects in the National Weight Control Registry. Obes Res 2002; 10: 78-82.

23. Kulick D, Hark L, Deen D. The bariatric surgery patient: a growing role for registered dietitians. J Am Diet Assoc 2010; 110: 593-9.

24. Alfadda AA, Al-Dhwayan MM, Alharbi AA, et al. The Saudi clinical practice guideline for the management of overweight and obesity in adults. Saudi Med J 2016; 37: 1151-62.

25. Erlandson M, Ivey LC, Seikel K. Update on office-based strategies for the management of obesity. Am Fam Physician 2016; 94: 361-8.

26. Afshar S, Seymour K, Kelly SB, et al. Changes in physical activity after bariatric surgery: using objective and self-reported measures. Surg Obes Relat Dis 2017; 13: 474-83.

27. Fried M, Yumuk V, Oppert JM, et al. International Federation for Surgery of Obesity and Metabolic Disorders-European Chapter (IFSO-EC); European Association for the Study of Obesity (EASO); European Association for the Study of Obesity Obesity Management Task Force (EASO OMTF). Interdisciplinary European guidelines on metabolic and bariatric surgery. Obes Surg 2014; 24: 42-55.

28. Skroubis G, Sakellaropoulos G, Pouggouras K, et al. Comparison of nutritional deficiencies after Roux-en-Y gastric bypass and after biliopancreatic diversion with Roux-en-Y gastric bypass. Obes Surg 2002; 12: 551-8. 
29. Schweiger C, Weiss R, Berry E, et al. Nutritional deficiencies in bariatric surgery candidates. Obes Surg 2010; 20: 193-7.

30. Pena ME, Newaz TB. Diabetes and nutritional screening in post-bariatric patients. Curr Diabetes Rev 2017; 13: 213-24.

31. Smelt HJ, Pouwels S, Smulders JF. Different supplementation regimes to treat perioperative vitamin B12 deficiencies in bariatric surgery: a systematic review. Obes Surg 2017; 27: 254-62.

32. Sucandy I, Roberts KE, Nadzam G, et al. Micronutrient and metabolic status in morbidly obese patients undergoing bariatric surgery in a University Bariatric Program. Am Surg 2016; 82: 116-7.

33. Pilone V, Vitiello A, Monda A, et al. Laparoscopic adjustable gastric banding (LAGB) plus anterior fundoplication versus LAGB alone: a prospective comparative study. Surg Laparosc Endosc Percutan Tech 2016; 26: 216-20.

34. Nalepa P, Piechnik A, Kiersztan A. Wpływ operacji bariatrycznych na ustępowanie cukrzycy typu 2. Postepy Hig Med Dosw 2011; 65: 804-18.

35. Nimeri A, Al Shaban T, Maasher A. Laparoscopic conversion of one anastomosis gastric bypass/mini gastric bypass to Rouxen-Y gastric bypass for bile reflux gastritis. Surg Obes Relat Dis 2017; 13: 119-21.

36. Lauti M, Kularatna M, Hill AG, et al. Weight regain following sleeve gastrectomy - a systematic review. Obes Surg 2016; 26: 1326-34.

37. Gesquiere I, Foulon V, Augustijns P, et al. Micronutrient intake, from diet and supplements, and association with status markers in pre- and post-RYGB patients. Clin Nutr 2017; 36: 1175-81.

38. Janik MR, Stanowski E, Paśnik K. Present status of bariatric surgery in Poland. Videosurgery Miniinv 2016; 11: 22-5.

39. Thibault R, Pichard C. Overview on nutritional issues in bariatric surgery. Curr Opin Clin Nutr Metab Care 2016; 19: 484-90.

40. Jastrzębska-Mierzyńska M, Ostrowska L, Wasiluk D, et al. Dietetic recommendations after bariatric procedures in the light of the new guidelines regarding metabolic and bariatric surgery. Rocz Panstw Zakl Hig 2015; 66: 13-9.

41. Snyder-Marlow G, Taylor D, Lenhard J. Nutritional care for patients undergoing laparoscopic sleeve gastrectomy for weight loss. J Am Diet Assoc 2010; 110: 600-7.

42. Mechanick JI, Youdim A, Jones DB, et al. Clinical practice guidelines for the perioperative nutritional, metabolic, and nonsurgical support of the bariatric surgery patient - 2013 update: cosponsored by American Association of Clinical Endocrinologists, the Obesity Society, and American Society for Metabolic and Bariatric Surgery. Surg Obes Relat Dis 2013; 9: 159-91.

43. Chiappetta S, Stein J. Refeeding syndrome: an important complication following obesity surgery. Obes Fact 2016; 9: 12-6.

44. Mehanna HM, Moledina J, Travis J. Refeeding syndrome: what it is, and how to prevent and treat it. BMJ 2008; 336: 1495-98

45. Crook MA. Refeeding syndrome: problems with definition and management. Nutrition 2014; 30: 1448-55.

46. Jeznach-Steinhagen A, Bień K. Zalecenia dietetyczne dla osób po operacjach bariatrycznych. Med Metabol 2007; 11: 81-5.

47. Stavra Xanthakos A. Nutritional deficiencies in obesity and after bariatric surgery. Pediatr Clin North Am 2009; 56: 1105-21.
48. Moizé VL, Pi-Sunyer X, Mochari H, et al. Nutritional pyramid for post-gastric bypass patients. Obes Surg 2010; 20: 1133-41.

49. Soares FL, Bissoni de Sousa L, Corradi-Perini C, et al. Food quality in the late postoperative period of bariatric surgery: an evaluation using the bariatric food pyramid. Obes Surg 2014; 24: 1481-6.

50. Williams SE. Metabolic bone disease in the bariatric surgery patient. J Obes 2011; 2011: 634614.

51. Paśnik K, Stanowski E. Laparoskopowe leczenie otyłości. Postępy Nauk Med 2006; 18: 27-35.

52. Backes CF, Lopes E, Tetelbom A, et al. Medication and nutritional supplement use before and after bariatric surgery. Sao Paulo Med I 2016; 134: 491-500.

53. Gesquiere I, Darwich A, Van Der Schueren B, et al. Drug disposition and modelling before and after gastric bypass: immediate and controlled release metoprolol formulations. Br J Clin Pharmacol 2015; 5: 1021-30.

54. Homan J, Schijns W, Aarts EO, et al. An optimized multivitamin supplement lowers the number of vitamin and mineral deficiencies three years after Roux-en-Y gastric bypass: a cohort study. Surg Obes Relat Dis 2016; 12: 659-67.

55. Ramos NM, Magno FC, Cohen L, et al. Weight loss and nutritional anemia in patients submitted to Roux-en- $Y$ gastric bypass on use of vitamin and mineral supplementation. Arq Bras Cir Dig 2015; 28: 44-7.

56. Syrycja J, Bolanowski M. Wpływ operacji bariatrycznych na metabolizm kostny. Endokrynologia, Otyłość i Zaburzenia Przemiany Materii 2012; 8: 32-6.

57. Peterson LA, Zeng X, Caufield-Noll CP, et al. Vitamin D status and supplementation before and after bariatric surgery: a comprehensive literature review. Surg Obes Relat Dis 2016; 12: 693-702.

58. Costa TM, Paganoto M, Radominski RB, et al. Impact of deficient nutrition in bone mass after bariatric surgery. Arq Bras Cir Dig 2016; 29: 38-42.

59. Menegati GC, de Oliveira LC, Santos AL, et al. Nutritional status, body composition, and bone health in women after bariatric surgery at a University Hospital in Rio de Janeiro. Obes Surg 2016; 26: 1517-24.

60. Ivaska KK, Huovinen V, Soinio M, et al. Changes in bone metabolism after bariatric surgery by gastric bypass or sleeve gastrectomy. Bone 2017; 95; 47-54.

61. Cabra JA, Souza GP, Nascimento JA, et al. Impact of vitamin D and calcium deficiency in the bones of patients undergoing bariatric surgery: a systematic review. Arq Bras Cir Dig 2016; 29: 120-3.

62. Courcoulas AP, Christian NJ, Belle SH, et al. Weight change and health outcomes at 3 years after bariatric surgery among individuals with severe obesity. JAMA 2013; 310: 2416-25.

63. Walicka M, Franek E, Marcinowska-Suchowierska E. Operacja bariatryczna - i co dalej? Trendy w Endokrynologii 2015; 3: 11-6.

64. Raaijmakers LC, Pouwels S, Thomassen SE, et al. Quality of life and bariatric surgery: a systematic review of short- and longterm results and comparison with community norms. Eur J Clin Nutr 2016; 71: 441-9.

65. Pories WJ. Bariatric surgery: risks and rewards. Clin Endocrinol Metab 2008; 93: 89-96. 
66. Kindel TL, Oleynikov D. The improvement of gastroesophageal reflux disease and Barrett's after bariatric surgery. Obes Surg 2016; 26: 718-20.

67. Pataky Z, Locatelli L, Jung M, et al. Not all patients might benefit from gastric by-pass. Rev Med Suisse 2016; 12: 597-98, 600-1.

68. Carlin AM, Rao DS. Prevalence of vitamin D depletion among morbidly obese patients seeking gastric bypass surgery. Surg Obes Relat Dis 2006; 2: 98-103.

Received: 31.05.2017, accepted: 8.08.2017. 